\title{
Does Improved Periodontal Health affect Metabolic and Inflammatory Markers in Patients with Diabetes Mellitus? A Comparative Study
}

\author{
Dr. Shreeya Aryal, ${ }^{1}$ Dr. Ameena Pradhan, ${ }^{2}$ Dr. Surendra Man Shrestha ${ }^{3}$ \\ ${ }^{1,2}$ Assistant Professor, ${ }^{3}$ Professor and Head \\ Department of Periodontology \& Oral Implantology, People's Dental College, Kathmandu, Nepal
}

\begin{abstract}
Background: Periodontal disease is considered as the "sixth complication of diabetes mellitus". Patients suffering from diabetes mellitus (DM) are known to have increased susceptibility to infections which lead to poor metabolic control. Although it has been reported that improved metabolic control may lead to improved periodontal health it is still unclear whether the control of periodontal infections may improve the metabolic control of diabetes.

Aim: To compare the effect of periodontal therapy on metabolic and inflammatory markers in diabetic patients.

Materials and Methods: The study type was in vivo comparative study. 60 patients were selected for the study using simple random sampling method. The patients were grouped into control and case with 30 in each group. In all patients, plaque index, gingival index, probing pocket depth and clinical attachment level were assessed with the help of with The University of North Carolina probe (UNC-15) probe at baseline, 1 month and 3 month. Similarly, venous blood samples were taken for evaluating fasting glucose level, post prandial glucose level, glycated haemoglobin and C-reactive protein (CRP) at baseline, 1 month and 3 month. In treatment group, full mouth scaling and root planing was done and oral hygiene instructions was provided.

Results: The result of the study suggested that non surgical periodontal therapy helps in controlling glycemic level and CRP values in patients with diabetes mellitus.

Conclusion: Non-surgical periodontal treatment is associated with improved glycaemic control and reduction in CRP level in patients with DM.

Key Words: Diabetes mellitus, pocket depth, clinical attachment level, glycated haemoglobin, C-reactive protein, periodontal therapy
\end{abstract}

\section{INTRODUCTION}

In world population, Diabetes Mellitus (DM) and chronic periodontitis are common chronic diseases in adults. The prevalence of periodontal disease among individuals with inadequately controlled type 2 diabetes is generally higher than that of people free of any systemic disorder., ${ }^{1,2}$ The interrelationship between periodontitis and diabetes provides an example of systemic disease predisposing to oral infection, and once that infection is established, the oral

\section{Correspondence:}

Dr Shreeya Aryal

Department of Periodontology \& Oral Implantology,

People's Dental College, Kathmandu, Nepal

email: aryalshreeya@gmail.com

\section{Citation}

Aryal S, Pradhan A, Shrestha SM. Does improved periodontal health affect metabolic and inflammatory markers in patients with diabetes mellitus? A comparative study. J Nep Soc Perio Oral Implantol. 2017;1:2-6. infection exacerbating systemic disease. Periodontal disease is regarded as the "sixth complication of diabetes". ${ }^{3}$

While diabetes significantly impacts the periodontium, evidence also suggests the potential for periodontal infection to adversely influence glycemic control in diabetes. Periodontal treatment designed to decrease the bacterial challenge and reduce inflammation might restore insulin sensitivity over time, resulting in improved metabolic control.

C-reactive protein (CRP) is a well-known acute-phase reactant produced in response to inflammation due to various stimuli by the liver. Periodontal pathogens affect local and systemic immune and inflammatory response. Recent studies have shown that serum CRP levels are elevated in periodontal disease. Similarly, studies have shown elevation of CRP level in diabetes as well. However, in all the previous studies, CRP levels were measured by using high-sensitivity CRP assay kits with minimal detection limits of 0.1 to $3 \mathrm{mg} / \mathrm{L}$, which was much below the normal value of $10 \mathrm{mg} / \mathrm{L}$. These highsensitivity CRP assays need a proper laboratory setup, and 
these methods cannot be used as a routine chair-side test in the dental office.

The aim of this study was to compare the effect of periodontal therapy on metabolic and inflammatory markers in diabetic patients. Serum CRP levels in individuals with diabetes mellitus having periodontal disease was investigated by using a rapid chair-side diagnostic test kit with a lower detection limit of $6 \mathrm{mg} / \mathrm{L}$ and compared the CRP levels before and after periodontal therapy. Periodontal status of diabetic patients was evaluated in form of gingival index (GI, Loe and Silness), plaque index (PI, Silness and Loe), probing pocket depth (PPD), and clinical attachment level (CAL). Simultaneously, assessment of metabolic markers i.e. fasting glucose level, post prandial glucose level, glycated haemoglobin (HbAlc) was done before and after scaling and root planing.

\section{MATERIALS AND METHODS}

This was an in vivo comparative study. Before the study, ethical clearance was taken from Institutional Review Board of Institute of Medicine, Tribhuvan University, Kathmandu, Nepal.

Sixty diabetic subjects were selected from the patients reporting to Department of Periodontology and Oral Implantology in People's Dental College and Hospital. Simple random sampling method was used to collect the data. The inclusion criteria were: diabetic patients with minimum of 20 natural uncrowned teeth; patients with type 2 DM with HbAlc values: $6-8 \%$; no major diabetic complications; no history of systemic antibiotic administration within the last 3 months; no periodontal treatment 6 months prior to the study; and exclusion criteria included: diabetic patients having less than 20 natural uncrowned of teeth; patients with major diabetic complications; history of systemic antibiotic administration within the last 3 months; history of periodontal treatment 6 months prior to the study, and smoking habit. After taking informed consent, the individuals were randomly assigned into two groups - treatment (case) i.e group A and nontreatment (control) i.e. Group B with 30 patients in each group.

Periodontal parameters: PI, GI, PPD and CAL were recorded at baseline, 30 days and 90 days with The University of North Carolina probe (UNC 15) probe in both the groups. Also the metabolic parameters i.e. fasting glucose, post prandial glucose and HbA1C levels were recorded for both the groups at baseline, 30 days and 90 days. Similarly, CRP was recorded for patients in both the groups by simple chairside diagnostic test. Since the lower detection limit of CRP was 6 $\mu \mathrm{g} / \mathrm{mL}$, subjects with CRP values $<6 \mu \mathrm{g} / \mathrm{mL}$ were regarded sero-negative.

For assessing the effect of the periodontal treatment on metabolic control, no change in the hypoglycaemic drugs or diet was made for both groups during the study period. None of the groups received any additional guidance in managing their diabetic status. The subjects of both groups were analysed according to the methods used to control hyperglycaemia.

Periodontal treatment i.e. scaling and root planing and oral hygiene instructions was provided to the treatment group (Group A). The control group (Group B) received no periodontal treatment during the study period. After completion of the study, patients categorized in control group were given a full non-surgical and supportive periodontal treatment if needed.

\section{RESULTS}

All patients completed the study. None of the subjects reported any oral symptoms at any time during the trial such as toothache (including dental or gingival), painful symptoms (including oral pain, tenderness, soreness, discomfort or sensitivity), inflammation, allergy, abscess, altered taste or increased salivation, etc. Data analysis was done by SPSS software. The significance of differences over time (baseline, 1 month and 3 month) in each group was measured by Student's t-test and Pearson's Chi-square test. Comparison of mean was done between different groups. Probabilities less than $0.05(p<0.05)$ were considered significant. Probabilities less than $0.001(p<0.001)$ were considered highly significant.

The treatment group maintained relatively good oral hygiene and the PI, GI, PPD and CAL scores improved significantly among the treatment groups at 1 month and 3 months period.

Although the treatment group showed improvement in fasting glucose level, $p$ value at 1 month and 3 month was 0.285 and 0.93 respectively which is not significant.

$p$ value for $\mathrm{HbAlc}$ at baseline and 1 month is 0.53 and 0.25 respectively which in not significant whereas at 3 month, $p$ value is $0.029(<0.05)$ which is significant (Figure 1$)$.

Figure 1: Graphical representation of Glycated Haemoglobin of Group A and Group B at baseline, 1 month and 3 month

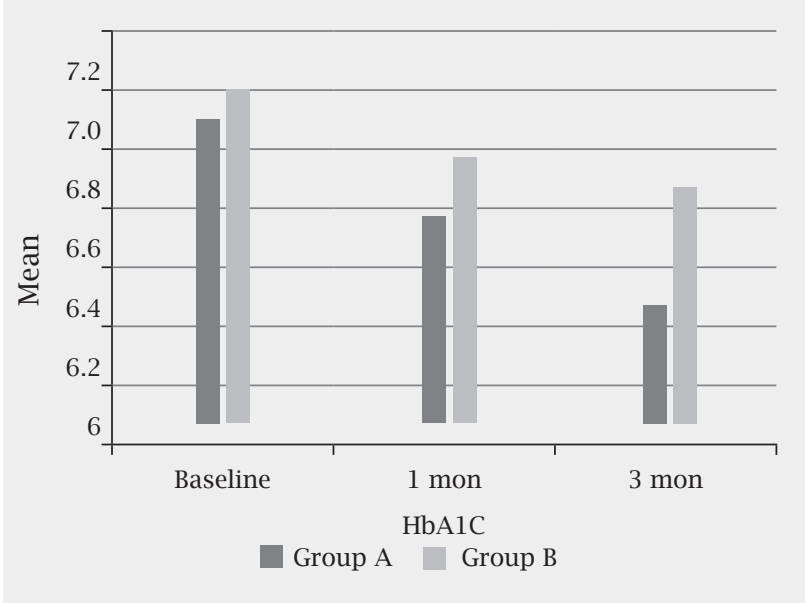


$p$ value for CRP at baseline and 1 month was 0.268 and 0.058 respectively which is not significant. $p$ value at 3 month is $0.00(p<0.001)$ which is highly significant. (Table 1$)$
Comparison of mean values of different variable between Group A and Group B at baseline,1month and 3 month (t-test and Chi-square test) is as represented in Table 2.

Table 1. C-reactive protein (negative $<6 \mu \mathrm{g} / \mathrm{mL}$, positive $\mathrm{CRP}>6 \mu \mathrm{g} / \mathrm{mL}$ )

\begin{tabular}{|c|c|c|c|c|c|c|}
\hline Parameters & \multicolumn{3}{|c|}{ Group A (Treatment Group) } & \multicolumn{3}{|c|}{ Group B ( Control Group) } \\
\hline $\begin{array}{l}\text { Total number of } \\
\text { counts }\end{array}$ & $\begin{array}{l}\text { Baseline } \\
\text { n (\%) }\end{array}$ & $\begin{array}{l}1 \text { Month } \\
\text { n (\%) }\end{array}$ & $\begin{array}{l}3 \text { Month } \\
\text { n (\%) }\end{array}$ & $\begin{array}{c}\text { Baseline } \\
\text { n (\%) }\end{array}$ & $\begin{array}{l}1 \text { Month } \\
\text { n (\%) }\end{array}$ & $\begin{array}{l}3 \text { Month } \\
\text { n (\%) }\end{array}$ \\
\hline Negative & $\begin{array}{c}17 \\
(56.66)\end{array}$ & $\begin{array}{c}23 \\
(76.66)\end{array}$ & $\begin{array}{c}29 \\
(96.66)\end{array}$ & $\begin{array}{l}15 \\
(50)\end{array}$ & $\begin{array}{c}16 \\
(53.33)\end{array}$ & $\begin{array}{c}15 \\
(50)\end{array}$ \\
\hline Positive & $\begin{array}{c}13 \\
(43.34) \\
\end{array}$ & $\begin{array}{c}7 \\
(23.34) \\
\end{array}$ & $\begin{array}{c}1 \\
(3.33) \\
\end{array}$ & $\begin{array}{c}15 \\
(50) \\
\end{array}$ & $\begin{array}{c}14 \\
(46.67) \\
\end{array}$ & $\begin{array}{c}15 \\
(50)\end{array}$ \\
\hline Total & 30 & 30 & 30 & 30 & 30 & 30 \\
\hline
\end{tabular}

Table 2: Comparison of mean values of different variable between Group A and Group B at baseline, 1month and 3 month (t -test and Chi square test)

\begin{tabular}{|c|c|c|c|}
\hline \multirow{2}{*}{ Indicators } & Group A & Group B & \multirow{2}{*}{$p$ value } \\
\hline & Mean (SD) & Mean (SD) & \\
\hline \multicolumn{4}{|l|}{ Plaque Index } \\
\hline Baseline & $1.9(0.65)$ & $2.08(0.43)$ & 0.228 \\
\hline 1 month & $1.29(0.72)$ & $2.02(0.46)$ & $<0.001$ \\
\hline 3 month & $1.30(0.65)$ & $2.16(0.46)$ & $<0.001$ \\
\hline \multicolumn{4}{|l|}{ Gingival Index } \\
\hline Base line & $1.74(0.58)$ & $2.07(0.45)$ & 0.13 \\
\hline 1 month & $1.29(0.68)$ & $12.02(0.45)$ & $<0.001$ \\
\hline 3 month & $1.19(0.59)$ & $2.16(0.46)$ & $<0.001$ \\
\hline \multicolumn{4}{|l|}{ Pocket Depth } \\
\hline Baseline & $6.87(1.74)$ & $7.9(1.35)$ & 0.13 \\
\hline 1month & $5(2.35)$ & $8.47(1.48)$ & $<0.001$ \\
\hline 3 month & $4.85(2.30)$ & $8.50(1.57)$ & $<0.001$ \\
\hline \multicolumn{4}{|c|}{ Clinical Attachment Level } \\
\hline Baseline & $6.23(1.67)$ & $6.67(1.49)$ & 0.22 \\
\hline 1 month & $5.23(2.01)$ & 7.33(1.64) & $<0.001$ \\
\hline 3 month & $4.73(1.96)$ & $7.37(1.73)$ & $<0.001$ \\
\hline \multicolumn{4}{|c|}{ Fasting Glucose Level } \\
\hline Baseline & 191.3(63.19) & 151.07(59.09) & 0.13 \\
\hline 1 month & $167.9(50.05)$ & $156.67(37.35)$ & 0.285 \\
\hline 3 month & $158.13(41.27)$ & $157.23(39.50)$ & 0.93 \\
\hline \multicolumn{4}{|c|}{ Glycated Haemoglobin } \\
\hline Baseline & $7.03(0.60)$ & $7.13(0.65)$ & 0.53 \\
\hline 1 month & $6.73(0.59)$ & $6.9(0.63)$ & 0.25 \\
\hline 3 month & $6.48(0.46)$ & $6.50(0.65)$ & $<0.05$ \\
\hline \multicolumn{4}{|c|}{ C reactive protein (Total Positive and Negative Count) } \\
\hline Baseline & $\begin{array}{l}\text { Negative-17 } \\
\text { Positive- } 13 \\
\end{array}$ & $\begin{array}{l}\text { Negative-15 } \\
\text { Positive- } 15 \\
\end{array}$ & 0.268 \\
\hline 1 month & $\begin{array}{c}\text { Negative- } 23 \\
\text { Positive- } 7\end{array}$ & $\begin{array}{c}\text { Negative- } 16 \\
\text { Positive- } 14 \\
\end{array}$ & 0.058 \\
\hline 3 month & $\begin{array}{c}\text { Negative- } 29 \\
\text { Positive- } 1\end{array}$ & $\begin{array}{c}\text { Negative- } 15 \\
\text { Positive- } 15\end{array}$ & $<0.001$ \\
\hline
\end{tabular}




\section{DISCUSSION}

The influence of diabetes on periodontal health has been discussed widely in the dental literature..$^{2,4-6}$ A number of studies reported a high incidence and severity of periodontal disease in diabetic patients as compared with non-diabetic controls. $^{5-8}$

There is substantial evidence to support diabetes as a risk factor for poor periodontal health, there is also evidence for periodontal infection adversely effecting glycaemic control in diabetes where this has been less extensively studied. ${ }^{9}$ These studies lead to a hypothesis that successful management of periodontal infection will lead to a reduction of the local symptoms of the disease and control the glucose metabolism.

More direct evidence regarding the effects of periodontal infection on glycaemic control in diabetes comes from treatment studies. There is evidence to support periodontal infection having adverse effect on glycaemic control. ${ }^{10,11}$ However, not all investigations report improvement in glycaemic control after periodontal treatment. ${ }^{9,10}$

Results of this study suggest that following periodontal therapy there was an improvement in glycaemic control in individuals with type 2 DM when compared with a nontreatment control group. ${ }^{11}$ The significant finding of this study is that the data supported the clinical improvement and significant reductions in levels of HbAlc in type 2 diabetes patients following mechanical subgingival treatment only. Our clinical trial provided the evidence that elimination of periodontal infection and improvement of periodontal status significantly reduced the HbAlc in the short term, thus improving diabetes metabolic control.

On the contrary, previous studies involving periodontal treatment alone reported improvement in periodontal status only ${ }^{11}$ whereas studies including systemic antibiotics accompanying mechanical therapy reported an improvement in both periodontal status and glycaemic control. ${ }^{12,13}$ Despite the variations in the design of the study, Stewart et al. (2001) ${ }^{14}$ reported a decrease in the level of HbAlc following the nonsurgical periodontal treatment in patients with type $2 \mathrm{DM}$.

CRP is well-established marker of inflammation produced in response to various stimuli. There have been several cross-sectional studies demonstrating elevated levels of CRP in periodontitis patients. ${ }^{15-17}$ These studies fall short in indicating that periodontitis was the cause for the observed serum CRP levels, as CRP levels fluctuate with aging, high blood pressure, alcohol use, smoking, low levels of physical activity, chronic fatigue, coffee consumption, elevated triglyceride levels, insulin-resistance diabetes, estrogen intake, high-protein diet, sleep disturbances, and depression.

However, to fully confirm that elevation in CRP is due to periodontal infection, it is essential to see whether periodontal treatment is effective in reducing CRP levels following successful periodontal therapy. Ebersole et al., ${ }^{17}$ Slade et al., ${ }^{16}$ Ide et al., ${ }^{18}$ found a positive correlation between CRP and periodontitis, but they failed to illustrate changes in CRP following treatment. Nagarale (2010) ${ }^{19}$ studied the efficacy of a chairside diagnostic test kit for estimation of CRP levels in periodontal disease where they studied the CRP value in terms of negative or positive and concluded that the CRP value did not improve on improvement of periodontal parameters after periodontal therapy.

In our present study, there was significant reduction in level of CRP in treatment group following scaling and root planing on evaluation at 1 month and 3 month interval. The fact has to be considered that CRP level increases with insulin resistance as well. As in the present study, we observed that there was significant reduction in level of HbAlc following scaling and root planing, similarly there was reduction in level of CRP as well.

The limitations of present study could be confounding variables like age, sex, medications, etc. which have not been considered.

\section{CONCLUSION}

Diabetes has long been identified as a complicating factor in the periodontal therapy by the periodontists. Uncontrolled diabetes is at a risk of developing periodontal disease exhibiting more severe and more extensive destruction of periodontal supporting tissues. Periodontal disease is considered to be a significant complication of diabetes. The results prove that there is significant relationship between glycaemic control and periodontal health. Non-surgical periodontal treatment is associated with improved glycaemic control in patients with DM. There was significant reduction in level of $\mathrm{HbAlc}$ following periodontal treatment. Also, there was significant reduction in CRP level in diabetes patients following periodontal therapy. 


\section{REFERENCES}

1. Ueta E, Osaki T, Yoneda K, Yamamoto T. Prevalence of diabetes mellitus in odontogenic infections and oral candidiasis. An analysis of neutrophil suppression. J Oral Pathol Medicine. 1993;22:168-74

2. Shlossman M, Knowler WC, Pettitt DJ, Genco RJ. Type 2 diabetes mellitus and periodontal disease. J Am Dent Assoc. 1990;121:532-6.

3. Loe H. Periodontal disease. The sixth complication of diabetes mellitus. Diabetes Care. 1993;16 (Suppl 1):329-34.

4. Emrich LJ, Shlossman M, Genco RJ: Periodontal disease in non insulin-dependent diabetes mellitus. J Periodontol. 1991;62:123-31.

5. Wu T, Dorn JP, Donahue RP, Sempos CT, Trevisan M. Association of serum C-reactive protein with fasting insulin, glucose, and glycosylated hemoglobin: the Third National Health and Nutrition Examination Survey, 1988-1994. Am J Epidemiol. 2002;155:65-71.

6. Cohen DW, Friedman LA, Shapiro J, Kyle GC, Franklin S. Diabetes mellitus and periodontal disease: two-year longitudinal observations. Part 1. J Periodontol. 1970;41:709-12.

7. Cianciola LJ, Park BH, Bruck E, Mosovich L, Genco RJ. Prevalence of periodontal disease in insulin- dependent diabetes mellitus (juvenile diabetes). J Am Dent Assoc. 1982;104:653-60.

8. Rylander H, Ramberg, P, Blohme G, Lindhe J. Prevalence of periodontal disease in young diabetics. J Clin Periodontol. 1987;14:38-43.

9. Taylor G W. Bidirectional interrelationships between diabetes and periodontal diseases: an epidemiologic perspective. Ann Periodontol. 2001;6:99-112.

10. Miller LS, Manwell MA, Newbold D, Reding ME, Rasheed A, Blodgett J, Kornman, KS. The relationship between reduction in periodontal inflammation and diabetes control: a report of 9 cases. J Periodontol. 1992;63:843-8.

11. Kıran M, Arpak N, Unsal E, Erdogan MF. The effect of improved periodontal health on metabolic control in type 2 diabetes mellitus. J Clin Periodontol. 2005;32(6):266-72.

12. Williams RC, Mahan CJ. Periodontal disease and diabetes in young adults. J Am Med Assoc. 1960;172:776-8.

13. Westfelt E, Rylander H, Blohme G, Jonasson P, Lindhe J. The effect of periodontal therapy in diabetics. Results after 5 years. J Clin Periodontol. 1996;23:92-100.

14. Stewart JE, Wager KA, Friedlander AH, Zadeh HH. The effect of periodontal treatment on glycemic control in patients with type 2 diabetes mellitus. J Clin Periodontol. 2001;28:306-10.

15. Noack B, Genco RJ, Trevisan M, Grossi S, Zambon JJ, De Nardin E. Periodontal infections contribute to elevated systemic C-reactive protein level. J Periodontol. 2001;72(9):1221-7.

16. Slade GD, Ghezzi EM, Heiss G, Beck JD, Riche E, Offenbacher S. Relationship between periodontal disease and C-reactive protein among adults in the Atherosclerosis Risk in Communities study. Arch Intern Med. 2003;163(10):1172-9.

17. Ebersole JL, Cappelli D. Acute-Phase reactants in infections and inflammatory diseases. J Periodontol. 2000;23:19-49.

18. Ide M, McPartlin D, Coward PY, Crook M, Lumb P, Wilson RF. Effect of treatment of chronic periodontitis on levels of serum markers of acute-phase inflammatory and vascular responses. J Clin Periodontol. 2003;30:334-40.

19. Nagarale G, Ravindra S, Thakur S, Setty S. Efficacy of a chairside diagnostic test kit for estimation of C-reactive protein levels in periodontal disease. J Indian Soc Periodontol. 2010;14(4):213-6. 